\title{
Legal Research Methodologies in European Union and International Law: Research Notes (Part 3)
}

\section{Tamara Hervey, Rob Cryer \& Bal Sokhi-Bulley}

Project

Dates

Project Leaders
Collaborative Doctoral Training Project (ID 06/160/S1)

1 October 2006 - 30 September 2008

Tamara Hervey (Professor of Law, University of Sheffield) Rob Cryer (Professor of International \& Criminal Law, University of Birmingham)

Bal Sokhi-Bulley (Lecturer in Law, Queen's University Belfast \& PhD Candidate, University of Nottingham)

Funding

Arts and Humanities Research Council (AHRC)

\section{Introduction}

This final research notes article reflects on the project at its completion. We have developed the materials (as discussed in our previous research notes articles) ${ }^{1}$, 'road tested' them at two workshops, held in Nottingham (June 2007) and Sheffield (June 2008), and considered the feedback from participants and our experience of the project as a whole.

\section{The second workshop}

The first workshop was described in our early research notes article (Hervey et al. 2008). This workshop modified the programme, taking into account feedback and experience from the first workshop. Again, the workshop consisted of three different types of sessions: whole-group sessions; small group activities; and paper presentation panels.

In the whole group sessions, we dropped the 'Thinking Hats' exercise, and instead developed an opening 'Roundtable Session'. In this session, two members of academic staff (Rob Cryer, Emilie Cloatre), at different stages in their careers, and a PhD student (Bal Sokhi-Bulley) talked about their own research from the point of view of the themes of the workshop. This was in response to several participants at the previous workshop who asked for presentations from the project coordinators on using different methodologies/approaches in their own research projects:

\footnotetext{
${ }^{1}$ For full text details of the first two research notes please see, Hervey et al. (2007) and (2008).
} 
"It would have been interesting to have a panel discussion by several academics about the significance of theory etc and the place it should take in research from their own perspective; people seemed to have different views on this".

We were surprised by how keen students were to receive more overt 'teaching', having set up the project so as to break down the 'them' and 'us' barriers between staff and students. Interestingly, and perhaps because of this, no one highlighted the Roundtable Session as either a particularly beneficial element of the workshop (or, to be fair, one that was not useful) in the workshop feedback. However, the Roundtable did prompt interesting discussion and questions from the audience and seemed to be an effective starting or warm-up session. Participants commented that it was a good introduction to the themes of the workshop and to the organisers themselves.

We also had two plenary sessions at which the small groups fed back their work to the workshop as a whole. These enhanced the feeling of the workshop as cohesive, but were not appreciated by all participants, some of whom found the large group not very conducive to productive learning.

In the instructions for the paper presentation panels (the most 'traditional' part of the workshop), we encouraged students to make an oral presentation based on the methodology or approach of their PhD. Students were asked to try to explain their thesis in the light of one or more of the categories used in our list of approaches in the Workshop Preparatory Materials (for a further explanation, see our earlier research notes 'Part 2' article; Hervey et al. 2008), or if the list does not anticipate a particular project, to use (and explain) their own categorisation. We specifically asked students to think about the following (these are the kinds of questions that may appear, in various guises, in viva voce examinations, or when work is presented at conferences):

- Why did you reject other approaches?

- Can you articulate the theoretical bases on which you began with your research (even if you were not aware of them at the time)?

- How do you think about (international or EU) law in your project? What research questions did this lead to, or what research questions meant that you found this approach the most helpful?

- What data do you use?

- What are you actually doing or going to do?

We also suggested that students might like to 'play' briefly with ideas about what their research would look like with a different approach. The idea was to encourage students to make use of the workshop preparation; and to encourage an appreciation for the value of all of these approaches for the disciplines of EU and international law.

Predictably, in feedback for both workshops, the presentations were the aspect that students appreciated the most. Students were impressed with how effectively the workshop helped them to prepare a PhD manuscript that will meet the requisite academic standards and to defend it in a viva voce examination.

"My presentation helped me to focus and build a strong basis for my theory chapter".

"[The most useful aspect of the workshop was] presenting to a discussant and establishing that my thesis addresses all the theoretical concerns raised for the purposes of a viva".

We asked three of the participants whose work is in EU law to write up their presentations for publication in JCER, and to reflect on how the workshop helped them to take forward their research. These reflections, which show some of the richness of approaches and substantive areas being considered by PhD students in EU law, follow this article. 
As in the first workshop, the most innovative aspect of the workshop was the small group activities, facilitated by members of staff, but very much based on collaborative learning through completing various tasks, some of which were more light-hearted than others. The most light-hearted, the quiz, had very low take-up this time, perhaps because more of the participants already knew each other, so were happy to use that time in unstructured networking, and did not need a further task at that stage of the workshop. We retained the Venn Diagrams exercise (described in detail in our earlier research notes article), and the statements debate, but significantly expanded the time available for each exercise. We also significantly increased the amount of time spent in small groups discussing the preparatory materials, and the questions on each reading, concerning its approach, research question, data, method and the benefits and drawbacks of this type of approach (see our earlier research notes article). Again we thought these exercises were highly effective in terms of observable learning on the part of the participants.

\title{
The feedback
}

As with the first workshop, the feedback demonstrated that the participants felt that they had increased their understandings of legal research methodologies in their discipline.

\footnotetext{
"The workshop ... supported and encouraged me to reflect on my theoretical approach to my work and to learn from others' experience".

"Each session was both fun and informative and has given me ideas on how to strengthen and sharpen my research".
}

In some cases, this was from what students felt was a very low base.

\begin{abstract}
"I came to this workshop without having a clear idea of legal research methodologies. After 2 days of the workshop, it highlights that theory is necessary in carrying out practical research".
\end{abstract}

\begin{abstract}
"Honestly speaking, I've not known that all such approaches to the research exist. Now I am familiar with them and I know that on the basis of what approach you use depends your outcome".
\end{abstract}

Again, this view was echoed in feedback from academic staff.

\author{
"I certainly gained from the workshop - it has helped me to reflect more on my own \\ methodologies/theoretical approaches".
}

\begin{abstract}
"Most beneficial: helping to (re)think my place on the theoretical spectrum. Great workshop. I wish I'd had such an opportunity as a student".
\end{abstract}

As we noted in our previous research notes article, one of the biggest challenges for the project was how to make the workshop useful for researchers at different stages of their careers. We tried hard to address this challenge in the second workshop, by being more explicit in the workshop materials and instructions about the different constituencies of participants, and what different participants might expect to get from the workshop. Although having the 'Roundtable Session' meant that in some ways we highlighted that some participants have more experience than others, we continued to insist that everyone, at whatever stage in their research career, can learn through reflection on theory and methodology and its practical application in real research projects. As with the first workshop, we worked very hard to create an atmosphere that was friendly, non-threatening and informal (as well as hard working, energetic and fun). Again, this seems to have been appreciated by the participants:

\footnotetext{
"As last year, the organisers were successful in getting that 'we are all here to learn' message across to the participants".
} 
Overall, the feedback as a whole was very positive, with many comments suggesting no need for future amendments:

"The workshop met my expectations to the maximum effect. Well-organised, engaging and with clear aims and objectives".

"The workshop exceeded my expectations".

"The workshop more than met my expectations. I think that it built well on the basis of last year's workshop and has become more useful as a result".

"It was a great learning experience".

"I did not expect to learn so much about theory, generally, my work in particular, and other people's work. I cannot think of anything that should have been different".

"All great. No need for change".

"All [the workshop was] useful in different ways. Thank you".

\section{The future?}

The workshops were attended by 69 students, 16 early career scholars, and 17 more established scholars. Although the AHRC funding is now finished, the partner institutions are currently exploring how they will continue to offer the workshop in future years. The workshop materials are freely available, for anyone who wishes to use them in their own institution, in whatever form, at http://www.sheffield.ac.uk/law/research/clic/research/projects/res_methodology. Please acknowledge the AHRC if you do so!

\section{Student Contributions}

To end this JCER Research Notes series, three additional contributions written by student participants (Rebecca Sanders, Stelios Andreadakis and Anatole Abaquesne De Parfouru) from the final workshop are included (see pages 205-217 of this publication). The three students are at various stages of their $\mathrm{PhD}$ research and each piece is intended to introduce the student's PhD topic and some of the methodological issues which the workshop has encouraged each of them to address.

\section{Bibliography}

Hervey, T., Cryer, R. \& Sokhi-Bulley, B. (2007). 'Legal Research Methodologies in European Union and International Law: Research Notes (Part 1)', Journal of Contemporary European Research, 3 (2), pp.161-165.

Hervey, T., Cryer, R. \& Sokhi-Bulley, B. (2008). 'Legal Research Methodologies in European Union and International Law: Research Notes (Part 2)', Journal of Contemporary European Research, 4 (1), pp.48-51 